\title{
D-insar based ground subsidence evaluation of different topographical sites with sentinel-1A/B platforms
}

\author{
Amardeep Singh Virk ${ }^{1 *}$, Amanpreet Singh ${ }^{2}$ and S.K Mittal ${ }^{3}$ \\ Research Scholar, IKG-PTU, Kapurthala, India ${ }^{1}$ \\ Deputy Controller (Controller of Examinations), IKG-PTU, Kapurthala, India ${ }^{2}$ \\ Professor and HOD, Department of Computer Science and Engineering, Rayat Bahra University, Mohali, India ${ }^{3}$
}

\section{(C)2018 ACCENTS}

\begin{abstract}
The compaction of subsoil by ground water extraction is a global problem. Satellite synthetic aperture radar (SAR) scenes using differential interferometric synthetic aperture radar (D-InSAR) are analysed to study groundwater extraction induced subsidence in Mexico City. Sentinel-1 sensor data acquired for the analysis between the months of June and September for the year 2016 and 2017. The achieved information corresponds to the subsidence velocity is of -28.32 cm/year in Mexico City. The maximum land subsidence of $-7.45 \mathrm{~cm}$ in 2016 and $-6.35 \mathrm{~cm}$ in 2017 is predicted which supports more than $30 \mathrm{~cm}$ annual subsidence claimed by other authors. In Gulaba-Marhi landslide prone region of Himachal Pradesh sentinel-1 data between June and July for the year 2017 and 2018 is processed with the same processing parameters to know the impact of vegetation, geographical conditions and coherence on the deformation detection. Landslide deformation analysis in Gulaba-Marhi region has shown subsidence between $-2.93 \mathrm{~cm}$ to $-8.26 \mathrm{~cm}$ in June-July 2017 and between $-1.35 \mathrm{~cm}$ and $-6.39 \mathrm{~cm}$ in June-July 2018. Some new displacement points have appeared in the year 2018. Dense vegetation, slope orientation and low coherence of image data has greatly affected the reliability of results.
\end{abstract}

\section{Keywords}

D-InSAR, DEM, Subsidence, Interferogram, Topography.

\section{Introduction}

Land subsidence occurs when large amount of subsurface water is withdrawn from the subsoil. Subsoil responsible for holding the ground intact compacts thus size and number of open pore spaces reduces; hence total storage capacity of the aquifer system permanently reduces. This May be the probable cause of declining groundwater levels. It May also result in ground failures due to subsidence $[1,2]$. There are some other causes leading to subsidence like drainage of organic soils, natural compaction, coal mining and sinkholes [3, 4]. Landslides and soil creep are downslope movements of soil, gravel and rock masses under the influence of gravity.

\section{*Author for correspondence}

This work was conducted in the Department of Electronics and Communication Engineering, Adesh Institute of Engineering and Technology, Faridkot, India and IKG-PTU Kapurthala, India under Research and User Support service provided by ESA.
The downslope movement of material termed as mass wasting which contributes the most in landscape alterations. Generally all rapid downslope mass wasting caused by fragile nature of rocks, excessive rain fall, moist ground due to snow melting, erosion of slope by various manmade disturbances like toe cutting for road construction, traffic vibrations and deforestation is described as landslide.

\subsection{Subsidence a problem}

With the occurrence of subsidence buildings are tilting in a wave like pattern, highways are collapsing water supply and drainage systems are disrupted. A major man-made cause of the occurrence of subsidence is the withdrawal of water/oil/gas fluids from subsurface [5, 1]. Ground subsidence results in irreversible damages to infrastructure, water resources, agricultural, industries and residential areas. Ground subsidence can even cause changes in velocity and the direction of groundwater flow [6]. Buildings have to be abandoned being unsafe and sometimes repaired to keep them intact after subsidence. Subsidence phenomenon affected many major cities such as Mexico City [7], Taipei of China 
[8], Bangkok of Thailand [9], Arizona of USA [10], Kolkata of India [11], Kathmandu valley of Nepal [12], Shanghai and Beijing of China [13, 14] and Damaneh City of Iran [15]. Hundreds of landslides have been reported in Himachal Pradesh and Utrakhand states of India due to excessive seasonal rainfall and cloud bursts in the month of JulySeptember 2017, 2018. Houses, cars, buses found damaged and buried, great loss to infrastructure, power lines, roads and public property including human lives [e.g. kotrupi, Simla, Marhi, Aut and Utrakanshi landslides].

\subsection{Subsidence in Mexico city}

The ground subsidence in Mexico is mostly due to the excessive withdrawal of groundwater and high thickness and low bearing capacity of sediments. Mexico City is built partially on the heavily saturated clay in the area of a former lake (Lago Texcoco) which is crumpling with excessive groundwater extraction. Figure 1 reveals that these buildings in Mexico City look curvy from left to right instead of a straight line view indicating subsided ground. Subsidence rates differ because of different pumping rates of groundwater, different thickness of clay formations in different areas and heavy weighted old buildings. Many incidents of buckled highways, water supply and waste-water drainage disruption, damaged colonial-era buildings have been reported in [16].

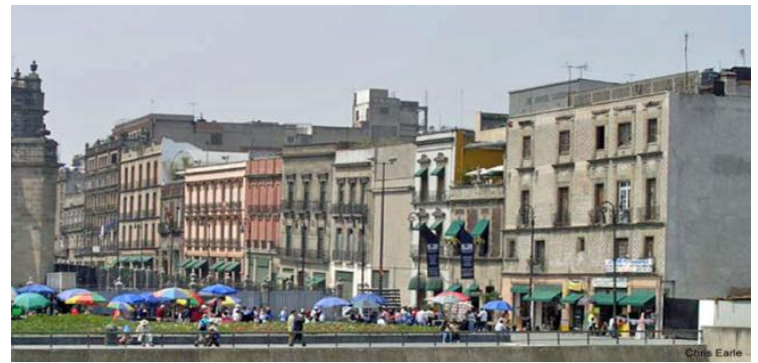

Figure 1 Features of buildings, showing wave like post subsidence effects in Mexico city. [Credit: Conifer-Hunting in Mexico]

where excessive groundwater have been withdrawn for years due to increasing population and declines in groundwater level have been observed due to intense agricultural activities causing ground subsidence. In 2013 for the first time cases of earth cracks, rupture of houses/roads and uplifting of well shells were observed as a result of subsidence.

Mexico City is documented well among the cities facing both aquifer decline caused by over-extraction of groundwater for long-terms and subsidence in [3, 17, 18]. Twenty-one locations of central Mexico City witnessed land subsidence but still fine-scale mapping of subsidence utilizing Interferometry synthetic aperture radar (InSAR) techniques is needed to better understand the phenomenon of land subsidence and to provide future urban development guidelines [19]. Land subsidence of more than 9 meters is estimated over the last decade in Mexico City, resulted in damages to buildings, roads, footpaths, sewerage systems, water drains and other infrastructure. Previous studies showed a subsidence rate of more than $30 \mathrm{~cm} /$ year and approximately 2.5 $\mathrm{cm} / \mathrm{month}$ in some parts of the city with the use of ERS data and SAR Interferometry [20].

\subsection{Subsidence in gulaba-marhi region}

This area having flat valleys in the lower part is situated in in a complex system of mountain ranges. The elevation of the Gulaba to Marhi varies from 2430 meters to 3660 meters. Gulaba slope is west (W) facing and Marhi slope is facing towards southwest (SW). The region bears around $15 \mathrm{~cm}$ of rain in the months of July and August during monsoon each year. Year 2018 has witnessed many landslides in Himachal Pradesh and Utrakhand states due to heavy seasonal rainfall. Amongst those a recent landslide occurred early morning on 29 June 2018 in the study area $30 \mathrm{~km}$ uphill from Manali in Himachal Pradesh on $29^{\text {th }}$ June 2018 is of more importance. Figure 2 shows the blocked Manali-Leh national highway-3 with landslide at chumbak morh in Marhi. Heavy rain has been observed in the area for the past 24 hours which caused the landslide. More then 2,000 vehicles were left stranded on either side of the blocked [21]. Between June-September, snow and rain water saturated rocks starts moving downslope resulting in sudden mass wasting. Multiple landslides and debris in the region can be seen alongside the NH-21 during this interval.

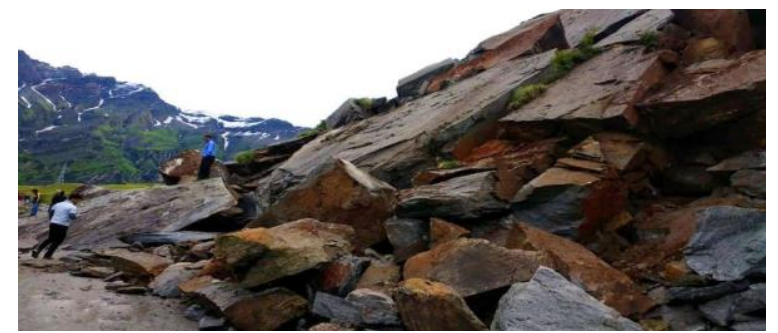

Figure 2 Manali-Leh highway NH-21 blocked by landslide at chumbak more near Marhi, (Source; Aqil Khan/Hindustan Times, Shimla) 
Virk et al.

\subsection{Subsidence measurement tools}

Ground Instrumentation such as global positioning system (GPS), levelling, air photo, extensometer and boreholes has been used for the ground displacement measurement. Advanced GPS, radar detectors and inclinometers are usually used to deduce ground subsidence related information [2, 22-24].

From the last decade, synthetic aperture radar interferometry has been preferred for land subsidence mapping and high precision ground displacement measurements in the radar line-of-sight (LOS) direction of sensor [2, 25-27]. D-InSAR due to its efficiency to obtain high-accuracy measurements has become a powerful tool for the spatial evaluation of land subsidence in large urban and agricultural areas [28-30, 3]. InSAR is thus an effective method that gives us insight to the surface distribution of the subsidence rates [31].

\subsection{Objectives and outline of the paper}

The objective of the paper is to implement and analyse D-InSAR to find land subsidence in two geographically separated sites and to analyse the effect of low coherence due to vegetation and poor scattering on the subsidence detection.

The outline of this study is as follows. The study sites and image coverage are described in Section 2, the datasets in section 3 and the InSAR methods are described in section 4 , subsidence results using DInSAR method are presented in Section 5 and conclusion and future scope follows in section 6 .

\section{Study area}

\subsection{Mexico city}

$\left(19 \mathrm{~A}^{\circ} 25^{\prime} 57.85 \mathrm{~N}, 99 \mathrm{~A}^{\circ} 07^{\prime} 59.71 \mathrm{~W}\right)$ is located in a large valley of Mexico (Valle de Mexico) in the high plateaus at the centre of Mexico City with an elevation of 2,240 meters (7,349 feet) above sea level [32]. The location of Mexico City on Google earth and sentinel-1 coverage is given in Figure $3(\mathrm{a}, \mathrm{b})$. The lower region of the valley receives less rainfall and is composed mainly of grasslands whereas upper southern region has mountains vegetated with pine and oak trees. The total coverage is about 16,807 $\mathrm{km} 2$ while the plain region accounts for $6390 \mathrm{~km}^{2}$. City witnesses rain season in the months of May to September. Local aquifers are the primary source of water supply and contribute to more than $70 \%$ of the water needs of the 112 million [33].

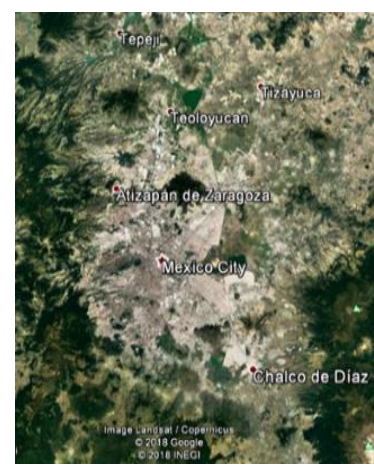

(a)

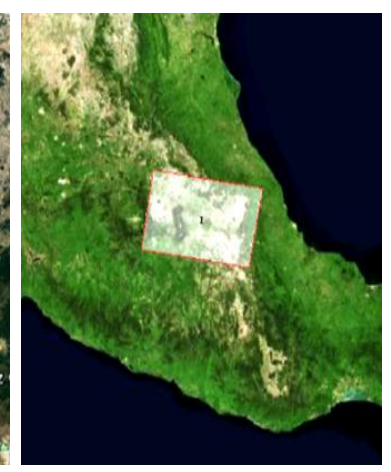

(b)
Figure 3 Location of the study area (a) Mexico city Google earth image (b) Mexico city coverage of sentinel-1 A/B, IWS image stacks (red rectangle)

\subsection{Gulaba-marhi region}

Gulaba $\left(32^{0} 19^{\prime} 3.04^{\prime \prime} \mathrm{N}, 77^{0} 12^{\prime} 12^{\prime \prime} \mathrm{E}\right)$ is located at, 20 kms away from Manali on Manali-leh national highway and Marhi $\left(32^{0} 20^{\prime} 55.8^{\prime \prime} \mathrm{N}, 77^{0} 13^{\prime} 5.6^{\prime \prime} \mathrm{E}\right)$ is $10 \mathrm{~km}$ away from Gulaba. Gulaba camp and Marhi town are situated in the north of the Manali at an altitude of $2810 \mathrm{~m}(9,221 \mathrm{ft})$ and $3333 \mathrm{~m}(10,935 \mathrm{ft})$ respectively up the beas river valley surrounded by intricate mountains of Himachal Pradesh. It is popular because of its unique geographic conditions and tourists picnic attractions. The temperature of the region varies from $-1.5^{\circ} \mathrm{C}$ to $16.5^{\circ} \mathrm{C}$ within the study area throughout the year. Gulaba-Marhi location on Google earth and sentinel-1 coverage is given in Figure 4(a, b).

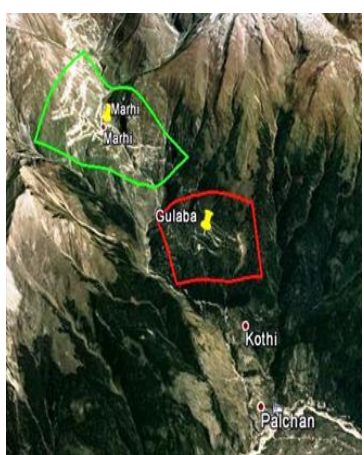

(a)

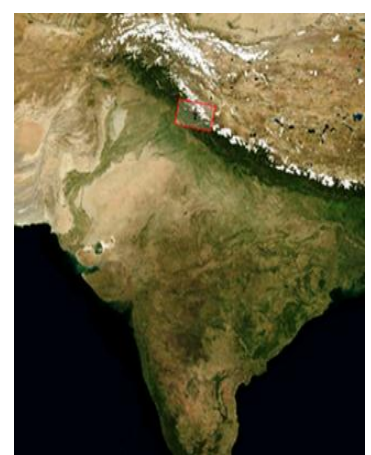

(b)
Figure 4 Location of study area (a) Gulaba (red polygon)-Marhi (green polygon) in Google earth, (b) Gulaba-Marhi region coverage of sentinel-1A image stacks (red rectangle) 


\section{Dataset}

Sentinel-1A/B single look complex (SLC) scenes are downloaded from copernicus program of European space agency (ESA) [34]. This study is conducted using c-band sentinel-1 SAR data acquired from constellation of two satellites sentinel-1A and sentinel-1B. The revisit time in the same orbit is only 12 days for each satellite and 6 days for the combined constellation. Data sets are being rapidly delivered, making it a good reserve for earth deformation monitoring. The c-band microwaves are capable of penetrating clouds and scan day and night irrespective of weather conditions. In order to study the land surface subsidence on both wet and dry conditions, we use four acquisitions of sentinel-1A/B data for subsidence mapping acquired with a spatial resolution of $5 \times 20 \mathrm{~m}$ in range and azimuth direction during descending pass.
Sentinel-1A/B (SLC) scenes with 96 day's separation (June 6 \& September 10-2016 and June 7 \& September 11-2017) are acquired in interferometric wide swath (IW) mode over the Mexico City (extent given in Figure $3(\mathrm{a}, \mathrm{b})$ ). The sentinel-1A for the year 2016 have been acquired with mean incidence angle of $44.088^{\circ}$, swath IW3 with track 143 while for 2017 with mean incidence angle of $44.079^{\circ}$, swath IW3 with track 143. All the sentinel-1 images in descending pass are acquired in VV single polarization with the azimuth and range pixel spacing of $13.99 \mathrm{~m}$ and $2.33 \mathrm{~m}$, respectively. The master and slave acquisition dates for both years and the related baselines information is given in Table 1. The perpendicular baseline $(\perp \mathrm{B})$ is relative to the first (master) image acquisition on 6 June 2016 and 7 June 2017.

\subsection{Mexico city data set}

Table 1 Mexico city sentinel-1 IW image data dates and perpendicular baselines.

\begin{tabular}{lllllc}
\hline Pair No. & Master & Slave & $\begin{array}{l}\perp \text { B } \\
(\mathbf{M})\end{array}$ & $\begin{array}{l}\text { Temporal } \\
\text { baseline(Days) }\end{array}$ & Sensor/track \\
\hline 1 & & & -44.87 & -96 & S1-A/143 \\
2 & 06 June 2016 & 10 Sept 2016 & -45.73 & -96 & S1-B/143 \\
\hline
\end{tabular}

\subsection{Gulaba-Marhi region data set}

Sentinel-1A single look complex (SLC) scenes with 48 days separation (June 13 \& July 31, 2017 and June 8 \& July 26, 2018) are acquired in interferometric wide swath (IW) mode over the Gulaba region (extent given in Figure 4(a, b)). The sentinel-1A SLC have been acquired for the year 2017 with mean incidence angle of $39.64^{\circ}$, swath IW2 in the track 136 while for the year 2018 with mean incidence angle of $39.65^{\circ}$, swath IW2 in the track 136. All the sentinel-1 images in descending pass are acquired in single VV polarization with the azimuth and range pixel spacing of $13.95 \mathrm{~m}$ and $2.33 \mathrm{~m}$ respectively. The master and slave acquisition dates for both years and the related baselines information is given in Table 2. The perpendicular baseline $(\perp \mathrm{B})$ is relative to the first (master) image acquisition on 13 June 2017 and 8 June 2018. Table 3 shows the properties of sentinel-1 interferometric wide swath (IW, SLC) products.

Table 2 Gulaba-Marhi sentinel-1A IW image dates and perpendicular baselines

\begin{tabular}{cccccc}
\hline Pair No. & Master & Slave & $\perp$ B (M) & $\begin{array}{c}\text { Temporal } \\
\text { baseline (Days) }\end{array}$ & $\begin{array}{c}\text { Sensor/ } \\
\text { track }\end{array}$ \\
\hline 1 & 13 June 2017 & 31 July 2017 & 8.49 & -48 & S1-A /136 \\
2 & 08 June 2018 & 26 July 2018 & 45.96 & -48 & S1-A /143 \\
\hline
\end{tabular}

Table 3 Properties of sentinel-1 interferometric wide swath (IW, SLC) products (Source; ESA, 2014/2016)

\begin{tabular}{|c|c|}
\hline Properties & Sentinel-1a/B \\
\hline Centre frequency & $5.405 \mathrm{GHz}$ \\
\hline Azimuth spacing & $13.99 \mathrm{~m}$ (azimuth) \\
\hline Range spacing & $2.33 \mathrm{~m}$ (slant range) \\
\hline Incident angle & $47.5^{\circ}($ mean $)$ \\
\hline Spatial resolution & $5 \mathrm{~m}$ (ground range) $\times 20 \mathrm{~m} \quad$ (azimuth) \\
\hline Band & $\mathrm{c}$ \\
\hline Pass & ascending/descending \\
\hline
\end{tabular}


Virk et al.

\begin{tabular}{ll}
\hline Properties & Sentinel-1a/B \\
\hline Polarizations & $\mathrm{HH}+\mathrm{HV}, \mathrm{VH}+\mathrm{VV}, \mathrm{HH}, \mathrm{VV}$ \\
Swath width & $250 \mathrm{~km}$ \\
\hline
\end{tabular}

\section{InSAR method}

In this method, earth surface is scanned from satellite by microwave pulses and reflected waves from Earth surface received by satellite are used to measure phase difference of two SAR images temporally separated. The phase history acquired with a minimal spatial baseline is used to obtain phase differences in the form of interferogram which along with coherence image can be used to evaluate the surface displacements along the satellite line of sight (LOS) $[35,36]$. LOS displacement is found from wrapped phase derived using phase unwrapping and other InSAR geometry using cosine laws. Image acquired with a very high coherence plays a key role in estimating displacement with high degree of reliability [37, 38].

The D-InSAR uses two SAR images and surface movement is determined by the spatial variation of phase across the image over a number of pixels. D-
InSAR removes topographic noise by use of a digital elevation model (DEM) and removes phase noise caused by atmospheric water vapour by using advanced spatial filtering techniques. D-InSAR is best suited to areas of interest where: Limited data is available with high image coherence, noise from atmospheric water vapour is low and noise from surface changes is low, such as in desert regions with little vegetation [39]. D-InSAR is efficient in areas with slow surface change. Image coherence gets lost in case of instant surface changes [40].

D-InSAR technique is applied in both the study areas for subsidence displacement detection using virtual machine provided by research and user support service (RUS) [41]. The main flow chart for the complete interferometric processing with all intermediate processing steps is given in Figure 5.

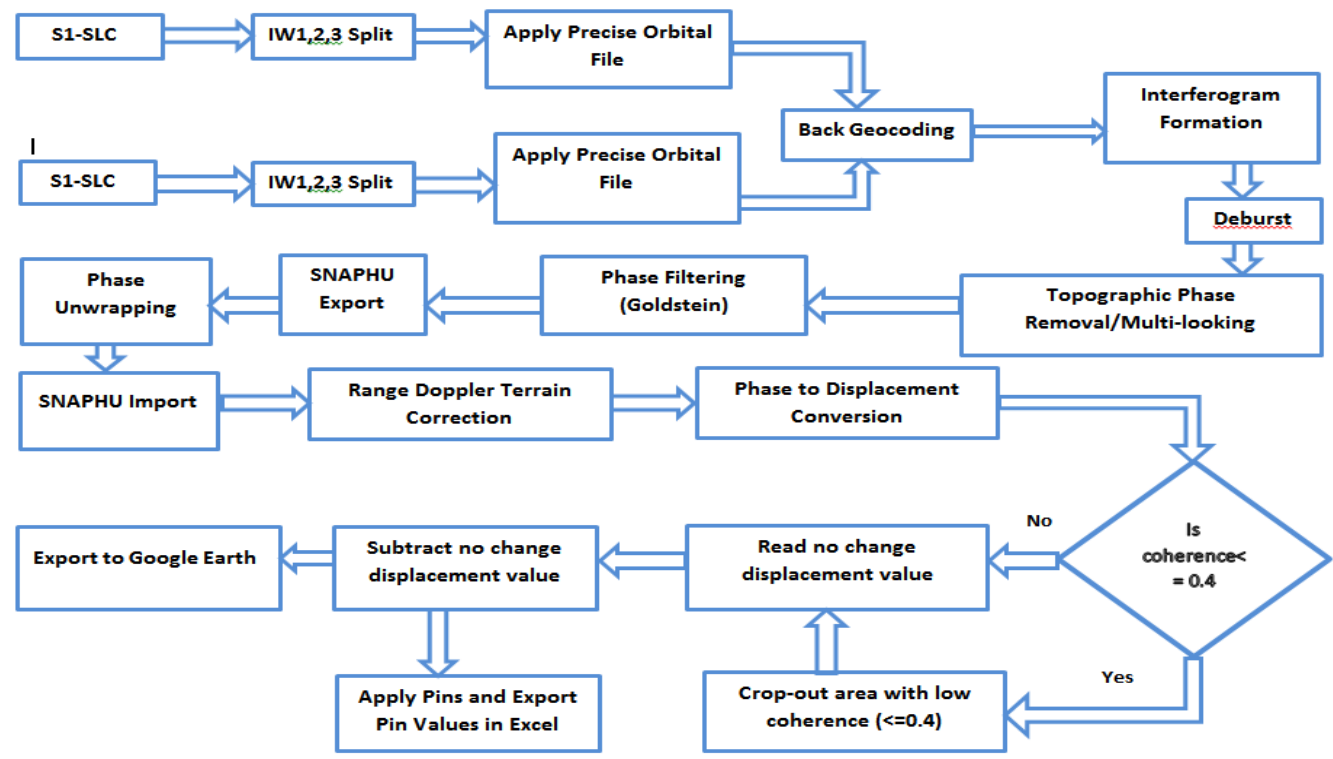

Figure 5 Main flow chart for subsidence map creation used in this study areas

The first processing step is to import SLC image in the SNAP environment and split it to IW swath and bursts covering AOI. Now each burst is processed as a separate SLC image and accurate satellite position and velocity information files are provided in the step apply precise orbital files. Back geocoding operator co-registers the second image (slave) with respect to the first image (master) of the same sub-swath using the orbital information of the two products and a DEM. Then an interferogram between the interferometric pair (master and slave) is produced holding phase information and estimated coherence image. In a single sub-swath individually focused complex burst images are separated with black-fill 
demarcation in between, which is removed in deburst step. The sufficient overlap of adjacent bursts and of sub-swaths ensures the continuous coverage of the ground preserving the phase information in area under investigation. Topographic induced phase from the debursted interferogram and speckle noise contained in the original SAR image is removed by topographic phase removal and multilook processing to improve the image interpretability. At phase filtering stage interferogram filtering is performed in order to reduce phase noise for visualization using Goldstein method [42]. Next step in this processing part is to export the data for Snaphu processing in order to apply phase unwrapping and import it back to SNAP [43]. Distances can be distorted in the SAR scenes due to variations in topography and the inclination of the satellite sensor. Range doppler terrain correction operator performs terrain corrections of the scenes to compensate for these distortions. Scenes are converted to geo-coordinates from SAR-coordinates so that geometrical representation of the image is as close as possible to the real world. Phase information in the wrapped interferogram will be converted to slant range displacement (d) in metric units by phase to displacement conversion using equation 1 .

$d=\frac{\lambda * \phi}{4 \pi}$

Where phi $(\phi)$ is the slant range displacement phase which you derived using phase unwrapping, $\mathrm{Pi}(\pi)$ is 3.14 and lambda $(\lambda)$ is the wavelength of the SAR signal $5.6 \mathrm{~cm}$.Low coherence $(<=0.4)$ areas are masked out in the geocoded scenes and phase and displacement bands are created with high coherence $(>=0.4)$ using band maths operator. Small displacement values present in pixels assuming no change are optionally subtracted from displacement values of the all pixels. Finally displacement, phase and coherence bands are exported to Google earth to display corresponding maps.

\section{Results and discussion}

Geocoded displacement map exported to Google earth extracted from 2016 and 2017 data are shown with colour legend for study location Mexico City in
Figure 6, 8 respectively. Subsidence is clearly seen in the middle of the city and extending towards southeast.

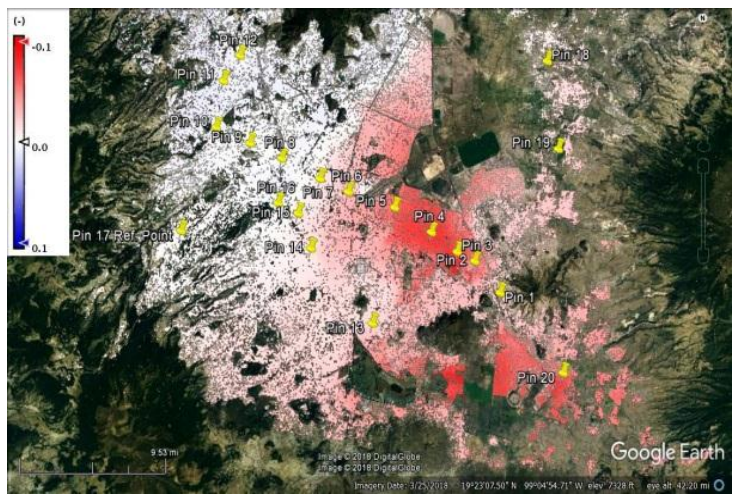

Figure 6 Displacement map Mexico city (2016)

Different subsidence rates have been observed throughout the city which is evident about the fact that water is being extracted unevenly. Western side farming vegetated area shows little to nil subsidence. Different pin points have been taken and the values of coherence, displacement and displacement mask after masking low coherence areas are given in Table 4 for the year 2016 and in Table 5 for the year 2017 respectively. Evaluation of displacement is carried out with high coherence $(\mathrm{coh}>=0.4)$ values and subtracting no change displacement value of reference point from actual deformation values to escape atmospheric noise and to have more reliable results.

Variation of subsidence at different pin points is shown graphically in Figure $7 \& 9$ for the year 2016 and 2017 respectively which clearly shows masked low coherence points resulting in zero displacement and it indicates extracted Disp_coh_msk value by subtracting Ref Pin 17 value from displacement. Maximum subsidence found is $-7.45 \mathrm{~cm}$ in 2016 and -6.35 in 2017 supporting more than $28 \mathrm{~cm}$ annual subsidence claimed by other authors $[15,16,19,44]$.

Table 4 Subsidence values (negative) at 20 measurement points extracted from S1-A SLC IW3 data set of year 2016. (positive values show uplift)

\begin{tabular}{lllll}
\hline Sr No. & Pin Name & Coherence $(\mathbf{C O H})$ & Displacement (Centimeter) & $\begin{array}{l}\text { Displ_Coh_Msk }(>= \\
\text { 0.4) }(\mathbf{C e n t i m e t e r )}\end{array}$ \\
\hline 1 & & & & -2.23 \\
2 & Pin 1 & 0.4175 & -1.31 & -5.96 \\
3 & Pin 2 & 0.5437 & -5.04 & 0.00 \\
4 & Pin 3 & 0.3645 & -7.09 & -7.45 \\
\hline
\end{tabular}


Virk et al.

\begin{tabular}{lllll}
\hline Sr No. & Pin Name & Coherence $\mathbf{( C O H )}$ & Displacement (Centimeter) & $\begin{array}{l}\text { Displ_Coh_Msk (>= } \\
\text { 0.4) (Centimeter) }\end{array}$ \\
\hline 5 & Pin 5 & 0.2261 & -4.97 & 0.00 \\
6 & Pin 6 & 0.7581 & -2.27 & -3.19 \\
7 & Pin 7 & 0.7249 & -0.05 & -0.97 \\
8 & Pin 8 & 0.7909 & 1.43 & 0.50 \\
9 & Pin 9 & 0.3016 & 1.12 & 0.00 \\
10 & Pin 10 & 0.9373 & 1.31 & 0.39 \\
11 & Pin 11 & 0.5683 & 1.71 & 0.79 \\
12 & Pin 12 & 0.8348 & 1.60 & 0.68 \\
13 & Pin 13 & 0.8117 & -1.47 & -2.40 \\
14 & Pin 14 & 0.8659 & -0.40 & -1.32 \\
15 & Pin 15 & 0.8169 & 0.06 & -0.86 \\
16 & Pin 16 & 0.8649 & 0.99 & 0.06 \\
17 & Ref Pin-17 & 0.9487 & 0.92 & 0.00 \\
18 & Pin 18 & 0.1311 & -0.37 & 0.00 \\
19 & Pin 19 & 0.1830 & -1.50 & 0.00 \\
20 & Pin 20 & 0.8456 & -5.96 & -6.89 \\
\hline
\end{tabular}

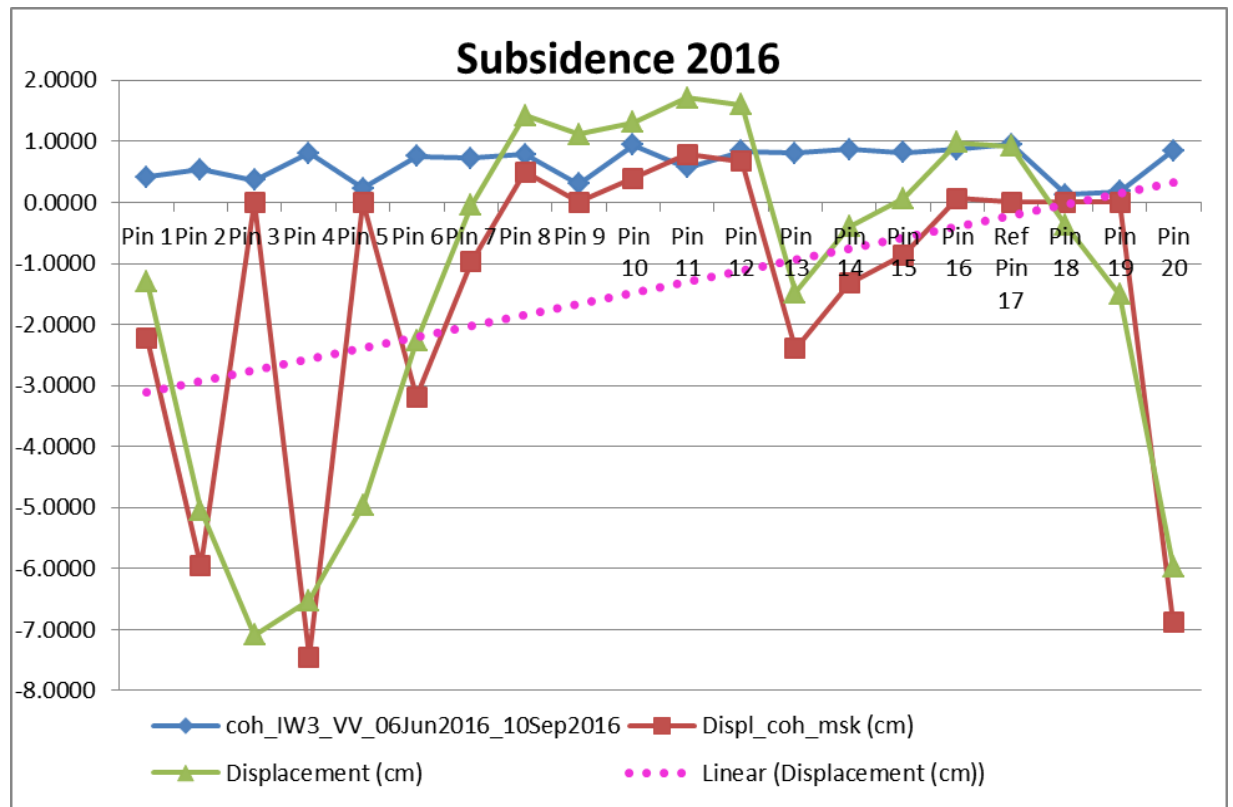

Figure 7 Graphical representation of Mexico city displacement points (2016)

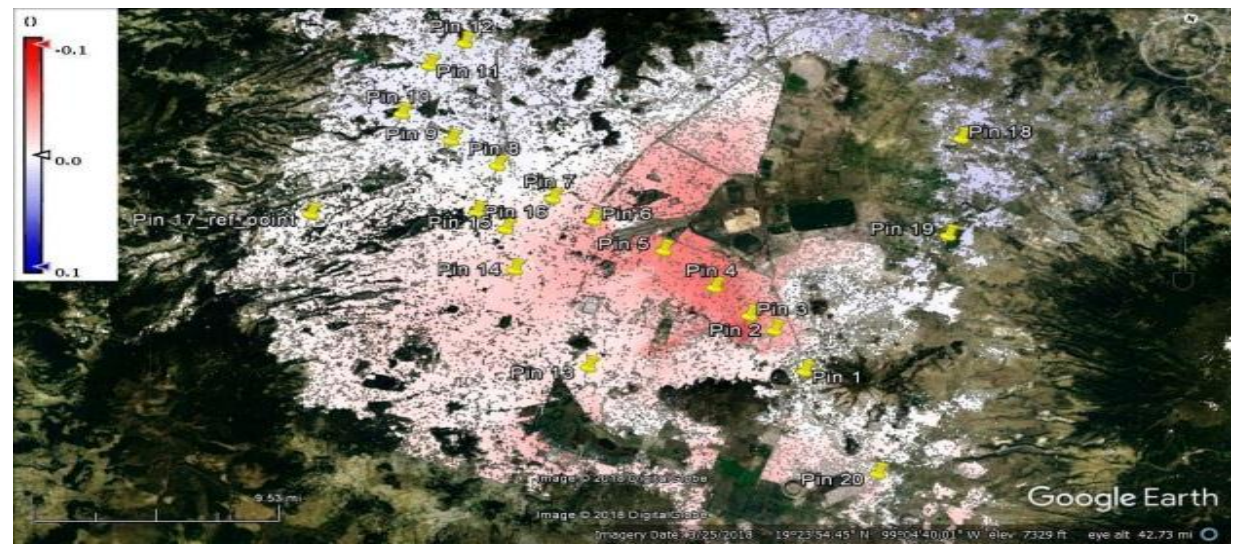

Figure 8 Displacement map Mexico city (2017) 
Table 5 Subsidence values (negative) at 20 measurement points extracted from S1-B SLC IW3 data set of year 2017. (positive values show uplift)

\begin{tabular}{lllll}
\hline Sr No. & Pin name & Coherence $(\mathbf{C o h})$ & Displacement (centimeter) & $\begin{array}{c}\text { Displ_coh_msk } \\
\text { 0.4) } \\
(\text { centimeter })\end{array}$ \\
\hline 1 & & & 0.00 \\
2 & Pin 1 & 0.1653 & -1.06 & -3.66 \\
3 & Pin 2 & 0.4432 & -4.64 & -6.35 \\
4 & Pin 3 & 0.6481 & -7.33 & -5.26 \\
5 & Pin 4 & 0.6111 & -6.24 & -4.89 \\
6 & Pin 5 & 0.4672 & -5.87 & -3.49 \\
7 & Pin 6 & 0.5058 & -4.47 & -1.07 \\
8 & Pin 7 & 0.7782 & -2.04 & 0.14 \\
9 & Pin 8 & 0.9272 & -0.83 & 0.00 \\
10 & Pin 9 & 0.1325 & -0.46 & 0.67 \\
11 & Pin 10 & 0.8991 & -0.31 & 0.60 \\
12 & Pin 11 & 0.6754 & -0.38 & 1.05 \\
13 & Pin 12 & 0.9219 & 0.08 & -1.00 \\
14 & Pin 13 & 0.8146 & -1.98 & -1.97 \\
15 & Pin 14 & 0.9070 & -2.95 & -1.05 \\
16 & Pin 15 & 0.4485 & -2.02 & -1.68 \\
17 & Pin 16 & 0.6127 & -2.66 & 0.00 \\
18 & Ref pin-17 & 0.9114 & -0.98 & 0.00 \\
19 & Pin 18 & 0.1202 & 0.66 & 0.00 \\
20 & Pin 19 & 0.1945 & 0.30 & -1.78 \\
\hline
\end{tabular}

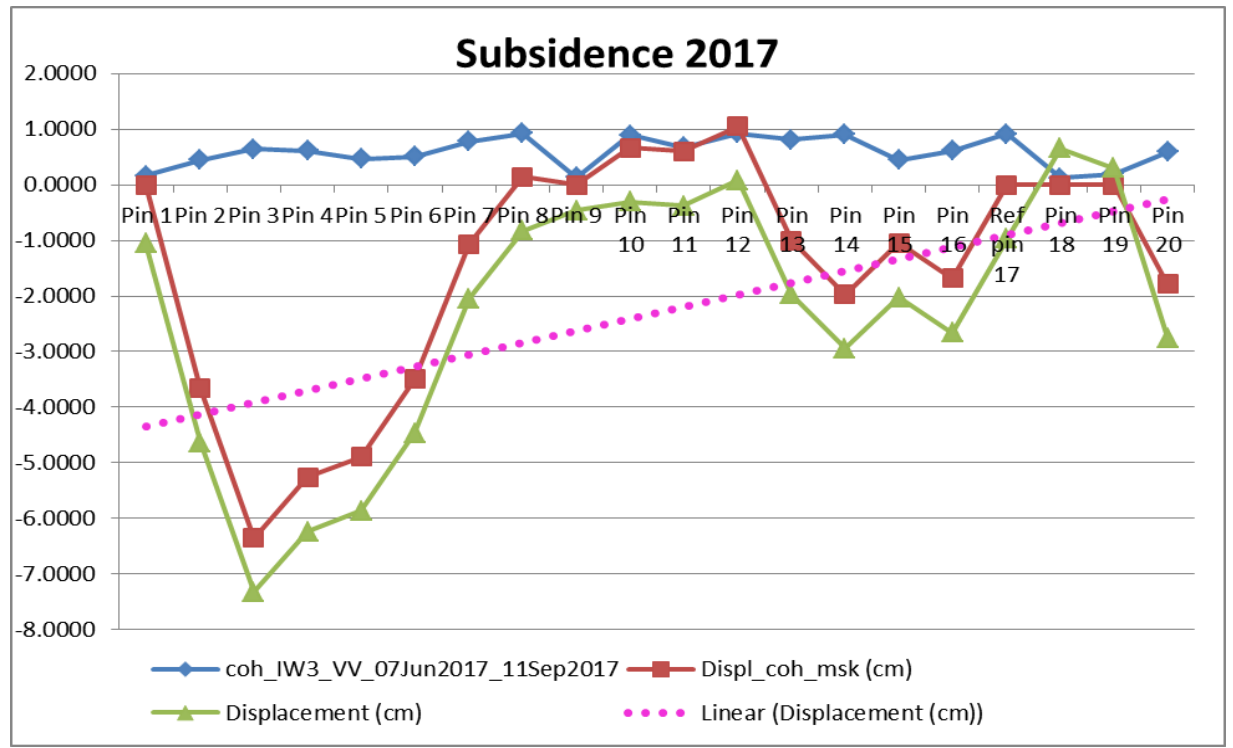

Figure 9 Graphical representation of Mexico city displacement points (2017)

Gulaba-Marhi region results of month June-July of the year 2017 are presented in similar way showing geocoded Google Earth displacement maps of Gulaba-Marhi in Figure 10. AOI has greatly affected the coherence of S1-A image data and hence the subsidence detection. Satellite scans during orbits that from north to south (descending passes), the SAR antenna pointing is usually fixed pointed to the right side of the track to the same. Thus, the same scene on the ground has been observed by the SAR antenna from the east during the descending passes 433 and slopes facing west and south-west in study area are poorly scanned. Areas of continuous low coherence introduce noise into the displacement maps in the area of interest (AOI), the low coherence areas are caused by vegetation over natural terrain. Although filtering and interpolation can be applied to the data set in these areas but it would amount to ornamental fix. For operational products, these areas can be excluded from results since they are devoid of any reliable information. Few subsidence points have been found alongside the slopes above the NH- 
Virk et al.

21 highway with coherence threshold of $>=0.4$ and masking displacement for these coherence values. Coherence and displacement $(\mathrm{cm})$ values at selected 30 Pin points are given in Table 6 for the year 2017. Predicted subsidence lies between $-2.93 \mathrm{~cm}$ to -8.26 $\mathrm{cm}$ during this 48 days interval. Figure 11 is a graphical representation of variation of coherence and displacement at the chosen 30 points.
Similarly results of months June-July of the year 2018 are presented as geocoded Google Earth displacement map of Gulaba-Marhi in Figure 12. Coherence and displacement $(\mathrm{cm})$ values at selected 30 Pin points are given in Table 7 for the year 2018 . Predicted subsidence lies between $-1.35 \mathrm{~cm}$ and -6.39 $\mathrm{cm}$ during this 48 days interval. Figure 13 shows variation of coherence and displacement at the chosen 30 points.

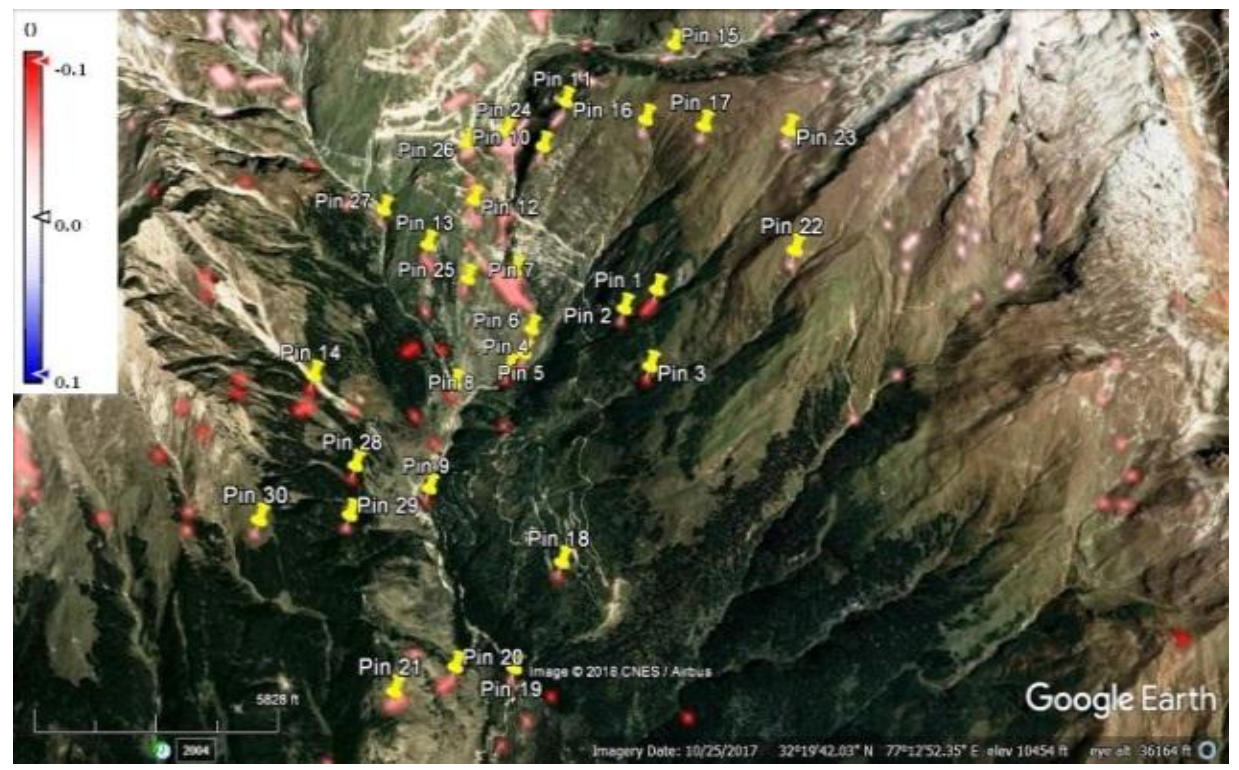

Figure 10 Displacement map Gulaba-Marhi region (13 June, 31 July 2017, 2017)

Table 6 Subsidence values (negative) at 30 measurement points extracted from data set of 13 June, 31 July-year 2017

\begin{tabular}{llll}
\hline Sr No. & Pin name & Coherence & \multicolumn{1}{c}{$\begin{array}{l}\text { Displacement } \\
\text { 13june_31july_2017 } \\
\text { (centimeter) }\end{array}$} \\
\hline 1 & & & -7.78 \\
2 & pin_1 & 0.4998 & -5.75 \\
3 & pin_2 & 0.4351 & -8.26 \\
4 & pin_3 & 0.4702 & -7.76 \\
5 & pin_4 & 0.4052 & -7.32 \\
6 & pin_5 & 0.4072 & -7.29 \\
7 & pin_6 & 0.4802 & -6.34 \\
8 & pin_7 & 0.5413 & -7.67 \\
9 & pin_8 & 0.4554 & -8.23 \\
10 & pin_9 & 0.5459 & -4.63 \\
11 & pin_10 & 0.5598 & -3.83 \\
12 & pin_11 & 0.4235 & -5.35 \\
13 & pin_12 & 0.4693 & -5.79 \\
14 & pin_13 & 0.5025 & -8.19 \\
15 & pin_14 & 0.4403 & -4.07 \\
16 & pin_15 & 0.4068 & -3.52 \\
17 & pin_16 & 0.4308 & -3.39 \\
18 & pin_17 & 0.4104 & -6.92 \\
19 & pin_18 & 0.7090 & -5.79 \\
20 & pin_19 & 0.4591 & -6.39 \\
\hline
\end{tabular}




\begin{tabular}{llll}
\hline Sr No. & Pin name & Coherence & $\begin{array}{l}\text { Displacement } \\
\text { 13june_31july_2017 } \\
\text { (centimeter) }\end{array}$ \\
\hline 21 & pin_21 & 0.4176 & -6.41 \\
22 & pi_22 & 0.4037 & -3.45 \\
23 & pin_23 & 0.6317 & -2.93 \\
24 & pin_24 & 0.4700 & -4.86 \\
25 & pin_25 & 0.4629 & -6.02 \\
26 & pin_26 & 0.4014 & -4.80 \\
27 & pin_27 & 0.4111 & -5.55 \\
28 & pin_28 & 0.4157 & -7.99 \\
29 & pin_29 & 0.4039 & -5.53 \\
30 & pi__30 & 0.4667 & -4.79 \\
\hline
\end{tabular}

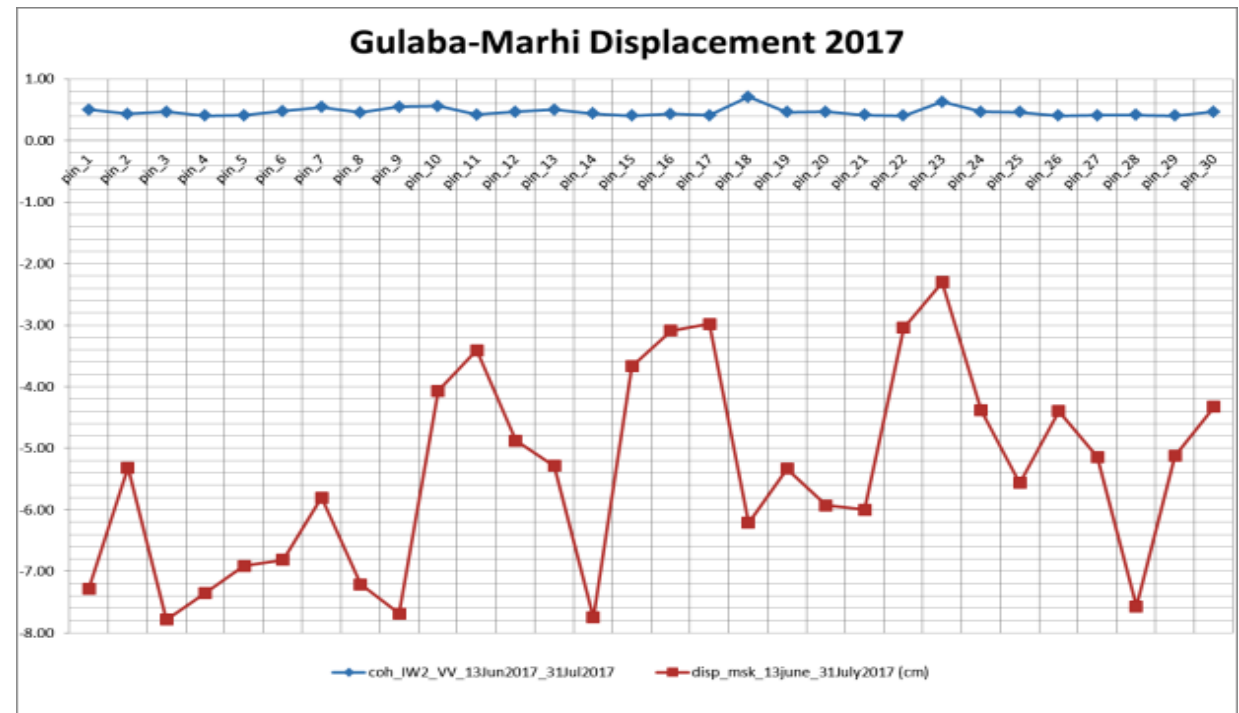

Figure 11 Graphical representations of displacement points (13 June, 31 July 2017, 2017)

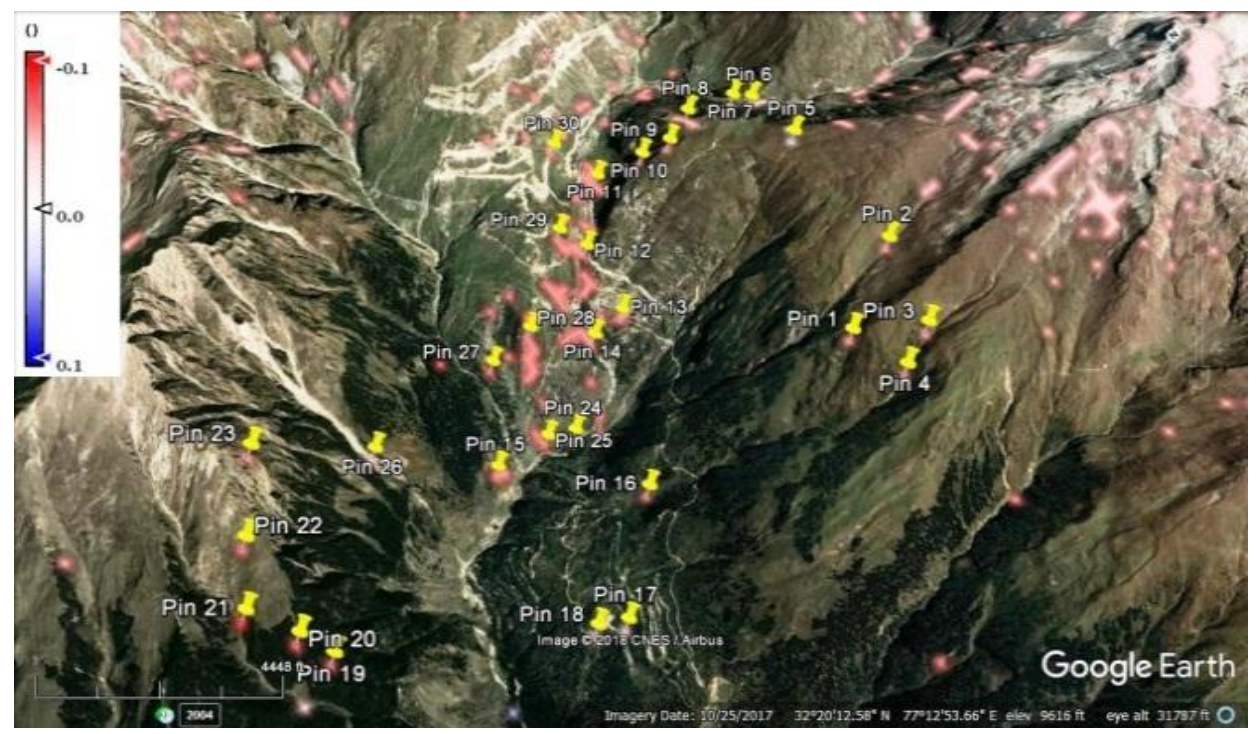

Figure 12 Displacement map Gulaba-Marhi region (08 June, 26 July 2018) 
Virk et al.

Table 7 Subsidence values (negative) at 30 measurement points extracted from data set of 08 June, 26 July-year 2018.

\begin{tabular}{|c|c|c|c|}
\hline Sr No. & Pin name & Coherence $(\mathrm{COH})$ & $\begin{array}{l}\text { Displacement } \\
\text { 8June_26July_2018 } \\
\text { (Centimeter) }\end{array}$ \\
\hline 1 & pin_1 & 0.5414 & -4.55 \\
\hline 2 & pin_2 & 0.4582 & -4.48 \\
\hline 3 & pin_3 & 0.4218 & -4.31 \\
\hline 4 & pin_4 & 0.5282 & -4.50 \\
\hline 5 & pin_5 & 0.4931 & -1.35 \\
\hline 6 & pin_6 & 0.4271 & -2.96 \\
\hline 7 & pin_7 & 0.4098 & -2.74 \\
\hline 8 & pin_8 & 0.5397 & -4.19 \\
\hline 9 & pin_9 & 0.4135 & -4.56 \\
\hline 10 & pin_10 & 0.4528 & -4.89 \\
\hline 11 & pin_11 & 0.5595 & -5.31 \\
\hline 12 & pin_12 & 0.4018 & -5.40 \\
\hline 13 & pin_13 & 0.4076 & -5.26 \\
\hline 14 & pin_14 & 0.4338 & -6.39 \\
\hline 15 & pin_15 & 0.4026 & -6.05 \\
\hline 16 & pin_16 & 0.4467 & -5.22 \\
\hline 17 & pin_17 & 0.4700 & -2.88 \\
\hline 18 & pin_18 & 0.4127 & -2.30 \\
\hline 19 & pin_19 & 0.4448 & -6.31 \\
\hline 20 & pin_20 & 0.4019 & -5.83 \\
\hline 21 & pin_21 & 0.4859 & -7.70 \\
\hline 22 & pin_22 & 0.4353 & -5.07 \\
\hline 23 & pin_23 & 0.4131 & -4.02 \\
\hline 24 & pin_24 & 0.5048 & -5.77 \\
\hline 25 & pin_25 & 0.4275 & -5.77 \\
\hline 26 & pin_26 & 0.4056 & -2.39 \\
\hline 27 & pin_27 & 0.4318 & -5.77 \\
\hline 28 & pin_28 & 0.4720 & -5.66 \\
\hline 29 & pin_29 & 0.4505 & -5.45 \\
\hline 30 & pin_30 & 0.4891 & -5.31 \\
\hline
\end{tabular}

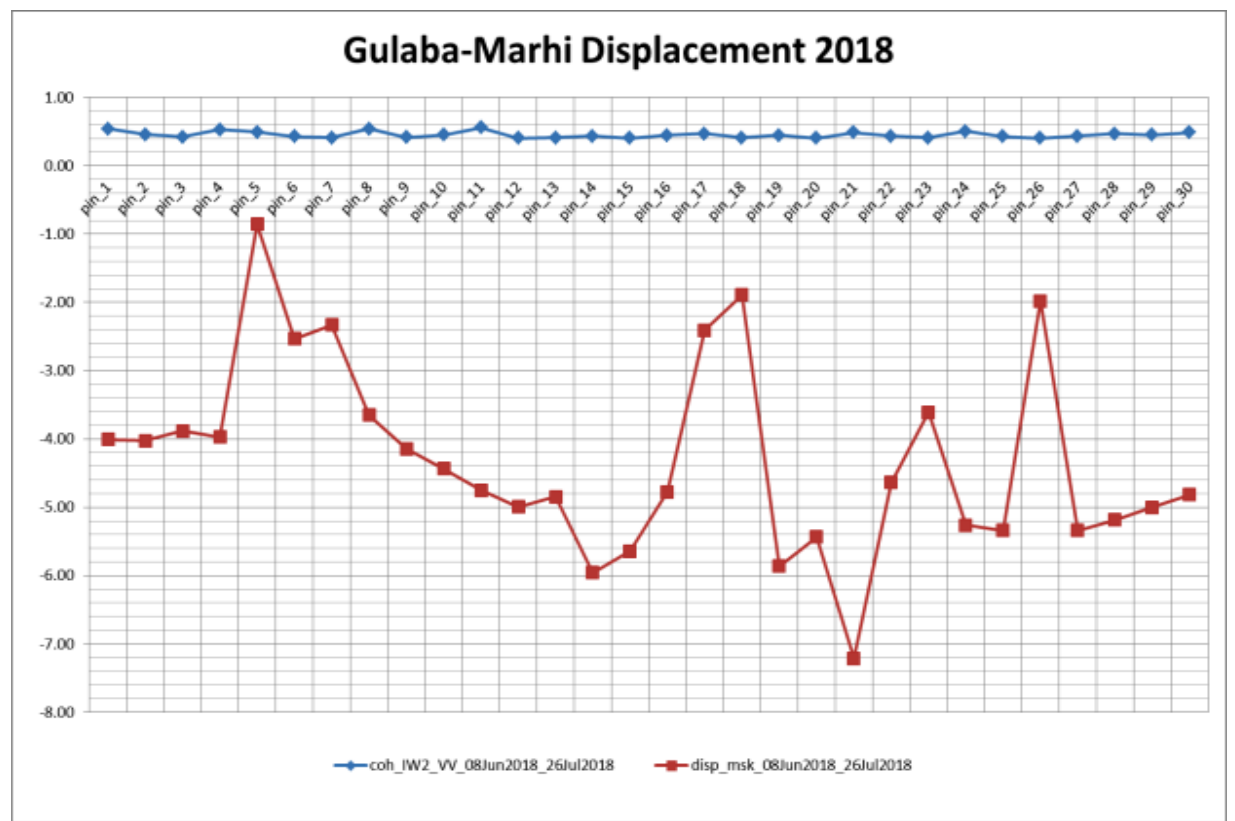

Figure 13 Graphical representation of displacement points (2018) 


\begin{abstract}
6. Conclusion and future work
D-InSAR method to estimate the process of subsidence at Mexico City is applied using 4 sentinel-1 images from the period 2016 \& 2017. Preliminary subsidence results indicate a rate of 25$30 \mathrm{~cm} /$ year with maximum value of land subsidence related displacement in city centre and in South-East areas. It is inferred that distinct variations in magnitude and the extent of the deformation change is there because water being unevenly extracted.
\end{abstract}

Image coherence is very low in Gulaba-Marhi region because it surrounded by high mountains, has less built up areas and poor back scattering due to the presence of west and south-west facing slopes in the study area. Subsidence between $-2.93 \mathrm{~cm}$ to $-8.26 \mathrm{~cm}$ in June-July 2017 and between $-1.35 \mathrm{~cm}$ and -6.39 in June-July 2018 has been evaluated. These displacement areas should be monitored for the detection of landslide. Some new subsidence points have appeared on Marhi road (Pin 13) in 2018 as a result a landslide have been reported there on 29th June 2018 confirming subsidence in the area.

In future, more investigations are needed with recent and high-resolution images with shorter revisit time like TerraSAR-X and ALOS L-band image data over the same area to collect high coherence points for DInSAR analysis so that the subsidence prone areas can be monitored and demarcated more precisely. Lband data are capable of penetrating vegetation cover thus somewhat reaching the ground surface is especially more suitable for mapping the surface deformations.

\section{Acknowledgment}

The sentinel-1 IWS, SLC data used were provided by sentinel-1 scientific data hub (ESA 2014/2016). The authors would like to thank the European space agency (ESA) for providing the sentinel data and cloud based virtual machine equipped with required software under research and user support service (RUS).

\section{Conflicts of interest}

The authors have no conflicts of interest to declare.

\begin{tabular}{|ll|}
\hline \multicolumn{2}{|l|}{ Nomenclatures } \\
$\perp B$ & Perpendicular baseline \\
Btemp & Temporal baseline \\
Greek Symbols & \\
$\theta$ & Angle of incidence, deg. \\
Abbreviations & \\
TOPS & Terrain observation with progressive scans \\
ALOS & Advanced land observing satellite \\
SAR & Synthetic aperture radar \\
\hline
\end{tabular}

\begin{tabular}{|ll|}
\hline InSAR & Interferometric SAR \\
D-InSAR & Differential interferometric SAR \\
VV/HH & Vertical-vertical/Horizontal-horizontal \\
DEM & World health organization \\
RUS & Research and user support service \\
SLC & Single look complex \\
ESA & European space agency \\
S1-A/B & Sentinel-1A/sentinel-1B \\
IWS & Interferometric wide swath \\
SNAP & Sentinel application platform \\
SRTM & Shuttle radar topography mission \\
\hline
\end{tabular}

\section{References}

[1] Adiyaman IB. Land subsidence and earth fissures due to groundwater pumping. The University of Arizona. 2012.

[2] Bell JW, Amelung F, Ramelli AR, Blewitt G. Land subsidence in Las Vegas, Nevada, 1935-2000: new geodetic data show evolution, revised spatial patterns, and reduced rates. Environmental \& Engineering Geoscience. 2002; 8(3):155-74.

[3] Osmanoğlu B, Dixon TH, Wdowinski S, Cabral-Cano E, Jiang Y. Mexico city subsidence observed with persistent scatterer in SAR. International Journal of Applied Earth Observation and Geoinformation. 2011; 13(1):1-12.

[4] Ng AH, Ge L, Li X, Zhang K. Monitoring ground deformation in Beijing, China with persistent scatterer SAR interferometry. Journal of Geodesy. 2012; 86(6):375-92.

[5] Bell JW, Amelung F, Ferretti A, Bianchi M, Novali F. Permanent scatterer InSAR reveals seasonal and longterm aquifer-system response to groundwater pumping and artificial recharge. Water Resources Research. 2008; 44(2):1-18.

[6] Holzer TL, Galloway DL. Impacts of land subsidence caused by withdrawal of underground fluids in the United States. Humans as Geologic Agents. 2005; 16:87-99.

[7] Ortega-Guerrero A, Rudolph DL, Cherry JA. Analysis of long-term land subsidence near Mexico city: field investigations and predictive modeling. Water Resources Research. 1999; 35(11):3327-41.

[8] Hou CS, Hu JC, Shen LC, Wang JS, Chen CL, Lai TC, et al. Estimation of subsidence using GPS measurements, and related hazard: the pingtung plain, southwestern Taiwan. Comptes Rendus Geoscience. 2005; 337(13):1184-93.

[9] Phien-Wej N, Giao PH, Nutalaya P. Land subsidence in Bangkok, Thailand. Engineering Geology. 2006; 82(4):187-201.

[10] Kataoka Y. Towards sustainable groundwater management in Asian cities-lessons from Osaka. International Review for Environmental Strategies. 2006; 6:269-90.

[11] Chatterjee RS, Thapa S, Singh KB, Varunakumar G, Raju EV. Detecting, mapping and monitoring of land subsidence in Jharia Coalfield, Jharkhand, India by spaceborne differential interferometric SAR, GPS and 
Virk et al.

precision levelling techniques. Journal of Earth System Science. 2015; 124(6):1359-76.

[12] Bhattarai R, Alifu H, Maitiniyazi A, Kondoh A. Detection of land subsidence in Kathmandu valley, Nepal, using DInSAR technique. Land. 2017; 6(2):1-17.

[13] Wang GY, You G, Shi B, Yu J, Tuck M. Long-term land subsidence and strata compression in Changzhou, China. Engineering Geology. 2009; 104(1-2):109-18.

[14] Du Z, Ge L, Ng AH, Xiaojing L, Li L. Mapping land subsidence over the eastern Beijing city using satellite radar interferometry. International Journal of Digital Earth. 2018; 11(5):504-19.

[15] Ghazifard A, Akbari E, Shirani K, Safaei H. Evaluating land subsidence by field survey and DInSAR technique in Damaneh City, Iran. Journal of Arid Land. 2017; 9(5):778-89.

[16] Sowter A, Amat MB, Cigna F, Marsh S, Athab A, Alshammari L. Mexico city land subsidence in 2014 2015 with Sentinel-1 IW TOPS: results using the intermittent SBAS (ISBAS) technique. International Journal of Applied Earth Observation and Geoinformation. 2016; 52:230-42.

[17] Yan Y, Doin MP, Lopez-Quiroz P, Tupin F, Fruneau $\mathrm{B}$, Pinel $\mathrm{V}$, et al. Mexico city subsidence measured by InSAR time series: joint analysis using PS and SBAS approaches. IEEE Journal of Selected Topics in Applied Earth Observations and Remote Sensing. 2012; 5(4):1312-26.

[18] Chaussard E, Wdowinski S, Cabral-Cano E, Amelung F. Land subsidence in central Mexico detected by ALOS InSAR time-series. Remote Sensing of Environment. 2014; 140:94-106.

[19] Cabral-Cano E, Dixon TH, Miralles-Wilhelm F, DíazMolina O, Sánchez-Zamora O, Carande RE. Space geodetic imaging of rapid ground subsidence in Mexico city. Geological Society of America Bulletin. 2008; 120(11-12):1556-66.

[20] Strozzi T, Wegmuller U. Land subsidence in Mexico city mapped by ERS differential SAR interferometry. In proceedings of international geoscience and remote sensing symposium 1999 (pp. 1940-2). IEEE.

[21] https://www.hindustantimes.com/india-news/over-2000-vehicles-stranded-due-to-landslide-on-manali-lehhighway/story-EFSGePY1hac4EQ0RSqd5zH.html. Accessed 09 July 2018.

[22] Carruth RL, Pool DR, Anderson CE. Land subsidence and aquifer compaction in the Tucson active management area, south-central Arizona, 1987-2005. US Geological Survey Scientific Investigations Report. 2007:1-4.

[23] Mittal SK, Singh M, Sardana HK, Dhingra S. Realization and installation of landslides instrumentation network at mansa devi (Haridwar), Indian landslides. Journal of Instrument Society of India. 2009; 39(4):256-7.

[24] Galloway DL, Hoffmann J. The application of satellite differential SAR interferometry-derived ground displacements in hydrogeology. Hydrogeology Journal. 2007; 15(1):133-54.
[25] Hoffmann J, Zebker HA, Galloway DL, Amelung F. Seasonal subsidence and rebound in Las Vegas valley, Nevada, observed by synthetic aperture radar interferometry. Water Resources Research. 2001; 37(6):1551-66.

[26] Rosen PA, Hensley S, Joughin IR, Li FK, Madsen SN, Rodriguez E, et al. Synthetic aperture radar interferometry. Proceedings of the IEEE. 2000; 88(3):333-82.

[27] Galloway DL, Burbey TJ. Regional land subsidence accompanying groundwater extraction. Hydrogeology Journal. 2011; 19(8):1459-86.

[28] Herrera G, Fernandez JA, Tomas R, Cooksley G, Mulas J. Advanced interpretation of subsidence in Murcia (SE Spain) using A-DInSAR data-modelling and validation. Natural Hazards \& Earth System Sciences. 2009; 9(3):647-61.

[29] López-Quiroz P, Doin MP, Tupin F, Briole P, Nicolas JM. Time series analysis of Mexico city subsidence constrained by radar interferometry. Journal of Applied Geophysics. 2009; 69(1):1-15.

[30] Cigna F, Cabral-Cano E, Osmanoglu B, Dixon TH, Wdowinski S. Detecting subsidence-induced faulting in Mexican urban areas by means of persistent scatterer interferometry and subsidence horizontal gradient mapping. In international geoscience and remote sensing symposium 2011 (pp. 2125-8). IEEE.

[31] Chaussard E, Amelung F, Aoki Y. Characterization of open and closed volcanic systems in Indonesia and Mexico using InSAR time series. Journal of Geophysical Research: Solid Earth. 2013; 118(8):3957-69.

[32] Calderhead AI, Martel A, Alasset PJ, Rivera A, Garfias J. Land subsidence induced by groundwater pumping, monitored by D-InSAR and field data in the Toluca valley, Mexico. Canadian Journal of Remote Sensing. 2010; 36(1):9-23.

[33] Calderhead AI, Therrien R, Rivera A, Martel R, Garfias J. Simulating pumping-induced regional land subsidence with the use of InSAR and field data in the Toluca valley, Mexico. Advances in Water Resources. 2011; 34(1):83-97.

[34] https://scihub.copernicus.eu/dhus. Accessed 30 February 2018.

[35] Massonnet D, Feigl KL. Radar interferometry and its application to changes in the Earth's surface. Reviews of Geophysics. 1998; 36(4):441-500.

[36] Chaussard E, Amelung F. Precursory inflation of shallow magma reservoirs at west Sunda volcanoes detected by InSAR. Geophysical Research Letters. 2012; 39(21):1-6.

[37] Wang M, Li T, Jiang L. Monitoring reclaimed lands subsidence in Hong Kong with InSAR technique by persistent and distributed scatterers. Natural Hazards. 2016; 82(1):531-43.

[38] Vassileva M, Giulio Tonolo F, Riccardi P, Lecci D, Boccardo P, Chiesa G. Satellite SAR interferometric techniques in support to emergency mapping. European Journal of Remote Sensing. 2017; 50(1):464-77. 
[39] Journault J, Macciotta R, Hendry MT, Charbonneau F, Huntley D, Bobrowsky PT. Measuring displacements of the Thompson river valley landslides, south of Ashcroft, BC, Canada, using satellite InSAR. Landslides. 2018; 15(4):621-36.

[40] Ng AH, Ge L, Du Z, Wang S, Ma C. Satellite radar interferometry for monitoring subsidence induced by longwall mining activity using Radarsat-2, Sentinel-1 and ALOS-2 data. International Journal of Applied Earth Observation and Geoinformation. 2017; 61:92103.

[41] https://rus-copernicus.eu/portal/. Accessed 09 July 2018.

[42] Goldstein RM, Werner CL. Radar interferogram filtering for geophysical applications. Geophysical Research Letters. 1998; 25(21):4035-8.

[43] Chen CW, Zebker HA. Phase unwrapping for large SAR interferograms: statistical segmentation and generalized network models. IEEE Transactions on Geoscience and Remote Sensing. 2002; 40(8):170919.

[44] http://www.esa.int/spaceinimages/Images/2014/12/Me xico_City_subsidence. Accessed 09 July 2018.

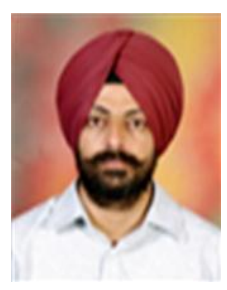

Mr. Amardeep Singh Virk bore in 1970 pursed AMIE in (EL\&TC) from The Institution of Engineers (INDIA), in 2000 and Master of Technology from Punjab Technical University Jalandhar in year 2010. He is currently pursuing Ph.D. and working as Assistant Professor and Head in Department of Electronics and Communication Engineering, Adesh Institute of Engineering and Technology, Under IKG-Punjab Technical University since 2006. He is an associate member of Institution of Engineers (IEIndia) since 2000. He has published more than 15 research papers in reputed International/National journals and conferences. His main research work focuses on Interferometric Synthetic Aperture Radar (InSAR) and Digital Image Processing. He has 12 years of teaching, 3 years of industrial and 7 years of research experience.

Email:virk_rana@yahoo.com

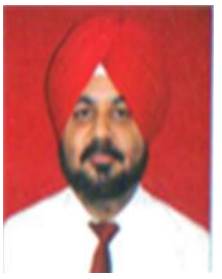

Mr. Amanpreet Singh born in 1970 completed B.E. (Power Electronics) from Nagpur University, Nagpur in 1992 with $2^{\text {nd }}$ position in the university, completed M. Tech (Electrical) from Punjab Agricultural University in 1998 and Ph.D (Electronics \& Instrumentation) from Punjab Technical University in 2009 and has published 7 papers out of the $\mathrm{Ph}$. D research work in International and National Journals. He is currently working as Deputy Controller (Conduct \& Secrecy) IKG-PTU Kapurthala, attended more than 30 International \& National Conferences/Workshops and published more than 100 papers in International/National Journals, International/National Conferences and published three Books on Electrical Engineering, digital electronics for degree and post graduate level students. He has 16 years of Academic/ Teaching/ Industrial experience along with 9 years of Administrative/Research experience. He is guiding $6 \mathrm{PhD}$ scholars in his research field of Digital Signal Processing.

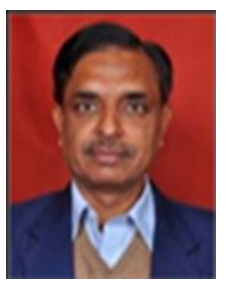

Mr. S.K Mittal born in 1957 completed his $\mathrm{M}$. Tech from IIT Roorkee in 1982 and $\mathrm{PhD}$ from Kurukshetra University, worked in CSIR, CSIO Chandigarh as Senior Scientist and have 35 years of research experience and currently working as Professor and Head in the Department of Computer Science and Engineering in Rayat Bahra University, Mohali. He has published 60 research papers in National/International Journals and conferences. His main research work focuses on Early Warning of Natural Disasters, Computer Architecture, Sensors and Instrumentation, Remote Sensing and Digital Image Processing. He is a life member of IETE and Computer Society of India. 